\title{
Limb apraxia in aphasic patients
}

\author{
Apraxia de membros em indivíduos afásicos
}

Karin Zazo Ortiz', Joana Mantovani-Nagaoka?

\begin{abstract}
Limb apraxia is usually associated with left cerebral hemisphere damage, with numerous case studies involving aphasic patients. The aim of this study was to verify the occurrence of limb apraxia in aphasic patients and analyze its nature. This study involved 44 healthy volunteers and 28 aphasic patients matched for age and education. All participants were assessed using a limb apraxia battery comprising subtests evaluating lexical-semantic aspects related to the comprehension/production of gestures as well as motor movements. Aphasics had worse performances on many tasks related to conceptual components of gestures. The difficulty found on the imitation of dynamic gesture tasks also indicated that there were specific motor difficulties in gesture planning. These results reinforce the importance of conducting limb apraxia assessment in aphasic patients and also highlight pantomime difficulties as a good predictor for semantic disturbances.
\end{abstract}

Keywords: apraxias; apraxia, ideomotor; aphasia; neuropsychological tests.

\section{RESUMO}

A apraxia de membros está frequentemente associada com lesões do hemisfério esquerdo, com inúmeros casos de pacientes afásicos. O objetivo deste estudo foi verificar a ocorrência da apraxia de membros em pacientes afásicos bem como a natureza desse distúrbio. O estudo foi realizado com 28 indivíduos afásicos e 44 controles pareados segundo a idade e a escolaridade. Todos os participantes foram avaliados com uma extensa bateria de apraxia de membros, consistindo de subtestes que avaliaram a compreensão e a produção dos aspectos léxico-semânticos relacionados aos gestos bem como produção motora propriamente dita. Os pacientes afásicos apresentaram dificuldades em tarefas envolvendo aspectos conceptuais da produção gestual. A dificuldade encontrada na imitação de gestos dinâmicos também indicou déficits no processamento gestual independente do déficit conceptual observado nestes pacientes. Esses resultados reforçam a importância da avaliação da apraxia de membros e apontam para a dificuldade de realização de pantomimas como indicativa de déficits semânticos.

Palavras-chave: apraxias; apraxia ideomotora; afasia; testes neuropsicológicos.

Limb apraxia is a movement disorder, usually associated with lesions to the left cerebral hemisphere, that cannot be accounted for by weakness, sensory loss, poor coordination of movement, or poor comprehension/attention to commands ${ }^{1}$.

The earliest systematic studies of limb apraxia were recorded by Liepmann who developed a classification of apraxias $^{2}$. He proposed three steps for the transition from intrapsychic process to motor execution, and selective disturbances of one of these steps yielded three variants of apraxia - ideational, motor/ideokinetic apraxia (ideomotor apraxia), and limb-kinetic apraxia². Drawing upon Liepmmann's original ideas, two levels of gesture processing were distinguished: a gestural-semantics level and a motor control level ${ }^{3}$. Although there is broad consensus on the interpretation of apraxia, which still provides a sound framework of reference for clarifying the nature of the disorder $^{4}$, the precise definitions of limb apraxias remain a focus of considerable debate ${ }^{5}$. At odds with other cognitive functions, interpretation of apraxia has suffered from a lack of a reliable model that does justice to its complexity. Rothi and Ochipa ${ }^{1}$ proposed a model, later reviewed ${ }^{6}$, in which five different patterns of impairment of gesture processing were postulated. The five predicted types of apraxia profiles postulated by these authors were: 1) deficit of action input lexicon: difficulty in discriminating and comprehending seen gestures with spared ability to imitate and execute gestures on verbal command; 2) impairment within the action semantic system: spared imitation but impaired execution on command coupled with problems in attributing meaning to gestures; 3 ) deficit of the action output lexicon: the derived picture differs from a

1 Universidade Federal de São Paulo, Departamento de Fonoaudiologia, São Paulo SP, Brasil.

Correspondence: Karin Zazo Ortiz; Departamento de Fonoaudiologia / UNIFESP; Rua Botucatu, 802; 04023-000 São Paulo SP Brasil; E-mail:karin.ortiz@unifesp.br

Conflict of interest: There is no conflict of interest to declare.

Support: FAPESP (2016/14998-1).

Received 24 February 2017; Received in final form 11 July 2017; Accepted 11 August 2017. 
semantic impairment only insofar as the gesture-meaning association is spared; as in the previous pattern, imitation is expected to be normal; 4) deficit of the visuo-motor conversion mechanism: isolated impairment of imitation is more overt for meaningless gestures; and 5) deficit of gestural buffer: impairment in all execution tasks either on command or on imitation coupled with preserved ability to perform judgment and categorization tasks. Given that the buffer is a temporary storage space, complex sequences should be more affected than single gestures.

Thus, many authors believe that, rather than a motor disorder, apraxia involves conceptual deficits that can be observed in motor production tasks ${ }^{6,7,8,10}$. One of the observations regarding apraxia is that impairments can be seen under some performance conditions but not others ${ }^{11}$, calling for a very specific and complete evaluation ${ }^{12,13}$.

Clinical studies demonstrate that limb apraxia is generally associated with a lesion in the left hemisphere and also that association with aphasia is not uncommon ${ }^{7,8,10,14,15,16 .}$ In fact, aphasic patients exhibiting oral communication deficits, besides problems communicating by gestures, are commonly seen in clinical practice.

In the same way as the gesture production model attempts to explain the processing of motor actions, different neuropsychological models contribute to the understanding of the mechanism involved in the processing of language and the different kinds of deficits secondary to disturbances in this processing ${ }^{17}$. Akin to the gesture production model, these models generally include a central semantic system (both input and output) interconnected to a lexical processing system.

The main objective of this study was to investigate the occurrence of limb apraxia in aphasic patients and to discuss the nature of the gestural processing deficits found in this population.

\section{METHODS}

The study was approved by the local Research Ethics Committee (Protocol Number 0170/05). After receiving full information about the study, written informed consent was obtained from all enrolled participants.

\section{Participants}

This study involved 44 healthy volunteers without neurological impairments, composing the control group (CG), and 28 aphasic patients forming the aphasic group (AG).

Since sociodemographic variables can influence the performance of individuals on cognitive tasks, including the limb praxis ${ }^{18,19}$, the healthy volunteers (CG) matched the aphasics for age, sex and educational background, according to the exclusion criteria: no records of neurological deficits, no histories of psychiatric treatment or psychotropic drug use, and no cognitive, behavioral and/or speech/language disorders, as determined by a brief neuropsychological battery.

This study included patients who had suffered a single left hemisphere stroke. Patients who presented with visual, motor or a severe comprehension disorder that prevented them from performing the tasks were excluded from the study. All patients selected for the study were right-handed and all were evaluated by a neurologist and underwent brain magnetic resonance imaging.

\section{General characteristics}

Of the 44 subjects comprising the control group (CG), $54.5 \%$ were women. Mean age was 54.48 years $(\mathrm{SD}=11.54)$ and education 7.27 years ( $\mathrm{SD}=4.89)$. Of the 28 patients comprising the aphasic group (AG), $42.9 \%$ were women. Mean age was 56.39 years $(\mathrm{SD}=10.83)$ and education 6.71 years $(\mathrm{SD}=4.15)$. Among the aphasic patients, $11(39.3 \%)$ had mixed aphasia, 7 (25\%) had anomic aphasia, 4 (14.3\%) had conduction aphasia, $3(10.7 \%)$ had transcortical sensory aphasia and $3(10.7 \%)$ had Broca's aphasia.

\section{Procedures}

Participants underwent a limb apraxia battery that was meant to evaluate all subcomponents of praxis processing, as based on the cognitive models ${ }^{1,6,20}$.

The battery ${ }^{18}$ comprised the following subtests:

\section{Lexical-semantic aspects related to gestural production}

Oral comprehension of actions and objects: out of four photographs shown on a card, the participant must identify the one corresponding to the action (10 items) or object (10 items) named by the evaluator. One point was given for each action and object correctly identified. One repetition of the verbal stimulus was allowed, if the participant requested it.

Naming of actions and objects: the participant must name the action (10 items) or object (10 items) shown by the evaluator. If the word was pronounced with phonemic paraphasias, the item was considered correct if it was possible to identify the correct name.

Recognition of object function: out of four photographs of objects displayed on a card, the participant must indicate the one corresponding to the function described by the evaluator. One point was given for each object corresponding to the function description correctly identified. One repetition of the verbal stimulus was allowed, if the participant requested it.

Definition of object function: the participant must describe the function of 10 items shown to them. One point was given for each object function correctly defined. If the word was pronounced with phonemic paraphasias, the item was considered correct if it was possible to identify the correct name. 
Comprehension of transitive gestures (i.e., gestures that involve the use of objects): Ten cards, each containing four photographs, are shown to the patient. In each figure, the same person uses the same object; however, in only one of these figures is the object being used correctly in terms of handling and spatial orientation. The participant must recognize and indicate the photo in which the object is being used correctly. One point was given for each correct gesture corresponding to the object use.

\section{Motor activity in response to verbal commands and imitation ${ }^{21}$.}

Ideomotor apraxia: the participant must demonstrate the use of a given object using gestures. For three items, the participant is allowed to hold the object in question in his/her hands, whereas for another three items, the evaluator simply states the object and the participants are asked to imagine the object in his/her hands and demonstrate (i.e., pantomime) its use. One point was given for each correct gesture corresponding to the use of the object.

Static imitation of meaningless gestures: the participant is asked to imitate the evaluator's hand in three different positions. One point was given for each part of each one of the three positions performed correctly.

Dynamic imitation of meaningless gestures: the participant is instructed to accurately imitate the hand movements performed by the evaluator. One point was given for each part of each one of the three movements performed correctly.

Ideational apraxia: performance of complex gestures is evaluated using three objects that are present and three objects that are absent (i.e., imagined). One point was given for each part of each one of the six actions performed correctly.

Symbolic gestures: the meaning of three symbolic gestures is assessed: waving hands to say goodbye, making a hand gesture to hail a taxi, and gesturing to make someone comes closer. One point was given for each gesture performed correctly.

Data collection was carried out on an individual basis by the same person.

All mistakes made were recorded.

Education levels were controlled and stratified into three bands: $1-4$ years; $5-8$ years and 9 years and over. The analysis of variance test (ANOVA) was applied to compare groups between tests, adopting a 5\% significance level. Multiple comparisons were calculated for those results that proved significant in order to identify these significant differences.

\section{RESULTS}

There were no statistically significant differences between the control and aphasic groups when comparing their age and years of education.
As education was stratified, the two-way ANOVA test was applied for a comparison between CG and AG groups. The results are shown in the Table.

\section{DISCUSSION}

The objective of this study was to analyze the performance of aphasic patients in a limb apraxia battery, controlling for the education variable. The key finding of this study was that aphasic patients had difficulty performing tasks involving complex sequences of ideational gestures and dynamic imitation of gestures. The difficulty found in performing pantomimes suggests semantic system impairments. Moreover, after controlling for education, this influence was particularly evident on complex motor tasks. These findings are discussed below.

The performance by the CG was superior to the AG on language tasks for naming actions and objects, as well as for recognizing and defining the function of instruments. Impaired language processing abilities secondary to aphasia are the most likely explanation for the poorer performance by the AG on these tasks. The "naming of actions and objects" subtest requires visual analysis of the graphic stimulus displayed, followed by access to the semantic system and output lexicon, where failures in lexical access are very common in aphasia. Thus, although the subtest is considered easy, employing common stimuli even for lower educational levels, in terms of pictorial representation ${ }^{22}$, as well as ease of manipulation and frequency ${ }^{23}$, the test proved sensitive for detecting the lexical difficulties present in the aphasic patients.

The "definition of object function" and "recognition of object function" subtests require the individual to access the function of a given instrument in the semantic system based on visual analysis of photographs. Many authors have attributed this semantic processing of actions/functions and instruments to the left cerebral hemisphere , $^{7,10,16,24,25}$. However, aphasic patients exhibited good performance on the "comprehension of transitive gestures", which assesses the processing of semantic gestures independently from expressive and receptive language abilities. Nevertheless, it is important to note that education appears to exert a "protective" effect on the impact of the lesion, given that in comparative analysis between the CG and AG, both education and the lesion influenced performance of the two groups on this subtest. However, qualitative analysis of data contained in the Table reveals that, although statistically different, the performances of the two groups converge with greater education. In other words, the impact of such lesions for these tasks appears to be lower in higher-educated aphasic individuals.

Besides these two subtests, education also exerted an effect on the performance of aphasic patients on the "ideomotor apraxia", "ideational apraxia" and "static imitation" subtests, where the greater the education, the better the performance. 
Table. A comparison of the performances of CG and AG for each of the subtests in the limb apraxia battery, considering education level and the ANOVA results.

\begin{tabular}{|c|c|c|c|c|c|c|c|}
\hline \multirow{2}{*}{ Variable } & & \multicolumn{3}{|c|}{ Education } & \multicolumn{3}{|c|}{ ANOVA - p-values } \\
\hline & & $(\leq 4)$ & $(5-8)$ & $(9+)$ & Group & Education & Group x education* \\
\hline \multicolumn{8}{|c|}{ Oral comprehension of actions and objects } \\
\hline \multirow{3}{*}{ CG } & Mean & 19.7 & 19.9 & 20.0 & & & \\
\hline & SD & 0.8 & 0.3 & 0.0 & & & \\
\hline & N & 15 & 15 & 14 & 0.3076 & 0.0608 & 0.7221 \\
\hline \multirow{3}{*}{$A G$} & Mean & 19.5 & 19.8 & 20.0 & & & \\
\hline & SD & 0.9 & 0.7 & 0.0 & & & \\
\hline & N & 11 & 9 & 8 & & & \\
\hline \multicolumn{8}{|c|}{ Naming of actions and objects } \\
\hline \multirow{3}{*}{$C G$} & Mean & 19.6 & 19.9 & 19.6 & & & \\
\hline & SD & 0.6 & 0.5 & 0.6 & & & \\
\hline & N & 15 & 15 & 14 & $0.0002^{*}$ & 0.4290 & 0.5802 \\
\hline \multirow{3}{*}{$A G$} & Mean & 16.9 & 17.6 & 16.9 & & & \\
\hline & SD & 4.8 & 3.4 & 4.1 & & & \\
\hline & N & 10 & 9 & 8 & & & \\
\hline \multicolumn{8}{|c|}{ Definition of object function } \\
\hline \multirow{3}{*}{ CG } & Mean & 9.8 & 10.0 & 10.0 & & & \\
\hline & SD & 0.4 & 0.0 & 0.0 & & & \\
\hline & N & 15 & 15 & 14 & $0.0002^{*}$ & 0.7714 & 0.9797 \\
\hline \multirow{3}{*}{$A G$} & Mean & 8.2 & 8.6 & 8.5 & & & \\
\hline & SD & 3.0 & 2.4 & 1.5 & & & \\
\hline & N & 11 & 9 & 8 & & & \\
\hline \multicolumn{8}{|c|}{ Recognition of object function } \\
\hline \multirow{3}{*}{ CG } & Mean & 9.9 & 9.9 & 9.9 & & & \\
\hline & SD & 0.3 & 0.3 & 0.3 & & & \\
\hline & N & 15 & 15 & 14 & $0.0024^{*}$ & 0.2992 & 0.2871 \\
\hline \multirow{3}{*}{$A G$} & Mean & 9.4 & 9.7 & 9.8 & & & \\
\hline & SD & 0.7 & 0.7 & 0.5 & & & \\
\hline & N & 11 & 9 & 8 & & & \\
\hline \multicolumn{8}{|c|}{ Comprehension of transitive gestures } \\
\hline \multirow{3}{*}{ CG } & Mean & 7.5 & 8.9 & 9.5 & & & \\
\hline & SD & 1.9 & 0.9 & 0.8 & & & \\
\hline & N & 15 & 15 & 14 & 0.1283 & $<0.0001 *$ & 0.7257 \\
\hline \multirow{3}{*}{$A G$} & Mean & 8.2 & 9.6 & 9.6 & & & \\
\hline & SD & 1.9 & 0.5 & 0.5 & & $(\leq 4)<(5-8)=(9+)$ & \\
\hline & N & 11 & 9 & 8 & & & \\
\hline Ideomoto & & & & & & & \\
\hline & Mean & 4.2 & 4.4 & 5.0 & & & \\
\hline$C G$ & SD & 1.0 & 0.9 & 0.9 & & & \\
\hline & N & 15 & 15 & 14 & 0.4413 & $0.0001 *$ & 0.1588 \\
\hline & Mean & 3.5 & 4.2 & 5.4 & & & \\
\hline$A G$ & SD & 1.1 & 1.1 & 0.7 & & $(\leq 4)<(5-8)<(9+)$ & \\
\hline & N & 11 & 9 & 8 & & & \\
\hline Ideationa & & & & & & & \\
\hline & Mean & 13.7 & 15.1 & 16.6 & & & \\
\hline$C G$ & SD & 2.6 & 1.7 & 1.5 & & & \\
\hline & N & 15 & 15 & 14 & $0.0011^{*}$ & $<0.0001 *$ & 0.3194 \\
\hline & Mean & 10.9 & 14.0 & 15.3 & & & \\
\hline$A G$ & SD & 2.6 & 1.9 & 1.8 & & $(\leq 4)<(5-8)<(9+)$ & \\
\hline & $\mathrm{N}$ & 11 & 9 & 8 & & & \\
\hline Symbolic & & & & & & & \\
\hline & Mean & 2.4 & 2.5 & 2.9 & & & \\
\hline$C G$ & SD & 0.5 & 0.5 & 0.4 & & & \\
\hline & $\mathrm{N}$ & 15 & 15 & 14 & 0.1242 & $0.0217 *$ & 0.9158 \\
\hline
\end{tabular}

Continue 


\begin{tabular}{|c|c|c|c|c|c|c|c|}
\hline \multirow{3}{*}{$A G$} & Mean & 2.3 & 2.2 & 2.6 & & \multirow{3}{*}{$(\leq 4)=(5-8)<(9+)$} & \\
\hline & SD & 0.6 & 0.7 & 0.5 & & & \\
\hline & N & 11 & 9 & 8 & & & \\
\hline \multicolumn{8}{|c|}{ Static imitation of meaningless gestures } \\
\hline \multirow{3}{*}{ CG } & Mean & 7.0 & 7.2 & 7.7 & & & \\
\hline & SD & 1.1 & 0.9 & 0.5 & & & \\
\hline & $\mathrm{N}$ & 15 & 15 & 14 & 0.1207 & $0.0008^{*}$ & 0.1146 \\
\hline \multirow{3}{*}{$A G$} & Mean & 5.8 & 7.2 & 7.6 & & \multirow{3}{*}{$(\leq 4)<(5-8)=(9+)$} & \\
\hline & SD & 1.9 & 0.8 & 1.1 & & & \\
\hline & $\mathrm{N}$ & 11 & 9 & 8 & & & \\
\hline \multicolumn{8}{|c|}{ Dynamic imitation of meaningless gestures } \\
\hline \multirow{3}{*}{ CG } & Mean & 3.5 & 5.1 & 5.4 & \multirow[b]{3}{*}{$0.0003 *$} & \multirow[b]{3}{*}{$<0.0001 *$} & \multirow[b]{3}{*}{0.2963} \\
\hline & SD & 1.2 & 1.2 & 0.9 & & & \\
\hline & $\mathrm{N}$ & 15 & 15 & 14 & & & \\
\hline \multirow{3}{*}{$A G$} & Mean & 1.8 & 4.3 & 4.5 & & \multirow{3}{*}{$(\leq 4)<(5-8)=(9+)$} & \\
\hline & SD & 1.2 & 1.3 & 1.2 & & & \\
\hline & $\mathrm{N}$ & 11 & 9 & 8 & & & \\
\hline
\end{tabular}

The "ideomotor apraxia" and "ideational apraxia" subtests involve both knowledge of the objects and instruments as well as the organization of the simple actions in sequences ${ }^{1}$. The former involves simple actions with (actual use) and without (pantomime) the presence of the objects, whereas the latter entails the production of actions in sequence to achieve a given objective, also including items with and without the use of the object. Qualitative comparison of the performance of the AG on the two tests showed that most errors (81.5\%) occurred in the pantomime production. The qualitative analysis also revealed that errors committed when performing pantomimes were predominantly of a body part as object type (63\%), followed by a spatial type (18\%), and other less frequent errors such as sequential errors. Difficulties accessing the transitive postural and movement representations ${ }^{17}$ are generally associated with the left hemisphere $\mathrm{e}^{7,18,26,27}$ and may have led, at least in part, to the body-part-as-object type errors committed by the aphasic patients ${ }^{28}$. The "ideational apraxia" test, involving a greater number of items susceptible to this error type, also revealed an influence of brain lesion in comparisons between the AG and CG. Thus, the difficulties of aphasic patients in performing pantomimes appears to the related to both cognitive deficits associated with education level, resulting in spatial type errors and language deficits, and consequently, failures in accessing the lexical-semantic system $^{29}$, which may be present in aphasias, causing a higher frequency of body-part-as-object type errors. Pantomimes share common factors with both apraxia and language $e^{30}$. Pantomiming a gesture is thought to place demands on the conceptual system, as the performer must generate a gesture based on representations of tools and actions ${ }^{11}$.

Comparison of the performance by the CG and AG on the "ideomotor apraxia" subtest revealed no group effect, i.e. the groups did not differ on this subtest, which might be explained by the task's low complexity, involving only single simple gestures. The more complex the motor action, i.e. the higher the number of steps involved in producing the gesture, the greater the demands on attentional cognitive abilities and working memory for successful execution, rendering such tasks susceptible to both educational level and brain lesions.

The performance of aphasic patients on the "static imitation" subtest was also influenced by the education variable, while the brain lesion had no impact on the abilities involved in this task. On this subtest, individuals have to observe a movement involving the hands and fingers performed by the evaluator, and subsequently reproduce it via visuo-motor conversion mechanisms ${ }^{6,7}$. Because the gestures are meaningless, they can be performed via the non-lexical route, as the action involves no knowledge of the instrument or its functions. Therefore, as observed in healthy individuals, the difficulties producing meaningless gestures are likely due to deficits in visuo-spatial processing described in loweducated individual ${ }^{26}$. Hence, the same education effects on performance in the CG for the subtests of the limb apraxia battery were observed in the AG.

Education also showed a "protective" effect on subtests, which were influenced by both this variable and brain lesions, where in higher-educated groups, the means of the two groups are closer. A brain lesion had an impact on the language test, which is to be expected given that aphasic individuals were involved, as well as on the "ideational apraxia" and "dynamic imitation" subtests, which, besides being more complex in terms of planning and motor execution, involved lexical-semantic aspects related to the instruments and visuo-spatial abilities associated with working memory. Some of the deficits expected in aphasia, such as lexical-semantic breakdowns, appear to have influenced the production of pantomimes in aphasic patients.

This is a cross-sectional study. In this study, we were only able to show that the aphasic patients presented with limb 
apraxia and some of the difficulties seemed to be related to semantic disorders that, as we know, also interfere in language processing in this population.

In conclusion, aphasic patients showed difficulties in limb gesture processing compared to healthy subjects matched for age and education. Pantomime and imitation of dynamic gestures were especially difficult for this population, where limb apraxia stems from disruptions to various stages of gesture performance.

These results reinforce the importance of carrying out a complete limb apraxia assessment in aphasic patients and also highlight pantomime difficulties as a good marker for semantic disturbances.

\section{References}

1. Rothi LJ, Heilman KM. Apraxia: the neuropsychology of action. East Sussex, UK: Psychology Press; 1997.

2. Goldenberg G. Apraxia and beyond: life and work of Hugo Liepmann. Cortex. 2003;39(3):509-24. https://doi.org/10.1016/S0010-9452(08)70261-2

3. De Renzi E, Lucchelli F. Ideational apraxia. Brain. 1988;111(5):1173-85. https://doi.org/10.1093/brain/111.5.1173

4. De Renzi E, Motti F, Nichelli P. Imitating gestures. A quantitative approach to ideomotor apraxia. Arch Neurol. 1980;37(1):6-10. https://doi.org/10.1001/archneur.1980.00500500036003

5. Wheaton LA, Hallett M. Ideomotor apraxia: a review.J Neurol Sci. 2007;260(1-2):1-10. https://doi.org/10.1016/j.jns.2007.04.014

6. Cubelli R, Marchetti C, Boscolo G, Della Sala S. Cognition in action: testing a model of limb apraxia. Brain Cogn. 2000;44(2):144-65. https://doi.org/10.1006/brcg.2000.1226

7. Goldenberg G. Imitating gestures and manipulating a mannikin - the representation of the human body in ideomotor apraxia. Neuropsychologia. 1995:33(1):63-72. https://doi.org/10.1016/0028-3932(94)00104-W

8. Goldenberg G, Hermsdörfer J, Spatt J. Ideomotor apraxia and cerebral dominance for motor control. Cogn Brain Res. 1996;3(2):95-100. https://doi.org/10.1016/0926-6410(95)00034-8

9. Goldenberg G, Strauss S. Hemisphere asymmetries for imitation of novel gestures. Neurology. 2002;59(6):893-7. https://doi.org/10.1212/WNL.59.6.893

10. Hanna-Pladdy B, Daniels SK, Fieselman MA, Thompson K, Vasterling JJ, Heilman KM et al. Praxis lateralization: errors in right and left hemisphere stroke. Cortex. 2001;37(2):219-30. https://doi.org/10.1016/S0010-9452(08)70569-0

11. Roy EA, Heath M, Westwood D, Schweizer TA, Dixon MJ, Black SE et al. Task demands and limb apraxia in stroke. Brain Cogn. 2000;44(2):253-79. https://doi.org/10.1006/brcg.2000.1230

12. Leiguarda R, Clarens F, Amengual A, Drucaroff L, Hallett M. Short apraxia screening test.J Clin Exp Neuropsychol. 2014;36(8):867-74. https://doi.org/10.1080/13803395.2014.951315

13. Perez-Marmol JM, Lopez-Alcalde S, Carnero-Pardo C, Canadas-De la Fuente GA, Peralta-Ramirez MI, Garcia-Rios MC. Creation and design of a test for the Evaluation of Upper Limb Apraxia (EULA) based on a cognitive model: a pilot study. Rev Neurol. 2015;60(2):66-74.

14. Geschwind N. The apraxias: neural mechanisms of disorders of learned movement. Am Sci. 1975;63(2):188-95.

15. Raymer AM, Maher LM, Foundas AL, Heilman KM, Rothi LJ. The significance of body part as tool errors in limb apraxia. Brain Cogn. 1997;34(2):287-92. https://doi.org/10.1006/brcg.1997.0919

16. Schnider A, Hanlon RE, Alexander DN, Benson DF. Ideomotor apraxia: behavioral dimensions and neuroanatomical basis. Brain Lang. 1997;58(1):125-36. https://doi.org/10.1006/brln.1997.1770
17. Basso A, Marangolo P. Cognitive neuropsychological rehabilitation: the emperor's new clothes? In: Basso A, Cappa S, Gianotti G, editors. Cognitive neuropsychology and language rehabilitation. East Sussex: Psychology Press; 2000. p. 219-29.

18. Mantovani-Nagaoka J. Ortiz KZ. The influence of age, gender and education on the performance of healthy individuals on a battery for assessing limb apraxias. Dement Neuropsychol. 2016;10(3):232-7. https://doi.org/10.1590/S1980-5764-2016DN1003010

19. Cera ML, Ortiz KZ, Bertolucci PH, Minett TS. Speech and orofacial apraxias in Alzheimer's disease. Int Psychogeriatr. 2013;25(10):1679-85. https://doi.org/10.1017/S1041610213000781

20. Canzano L, Scandola M, Gobbetto V, Moretto G, D'Imperio D, Moro V. The Representation of Objects in Apraxia: From Action Execution to Error Awareness. Front Hum Neurosci. 2016;10:39. https://doi.org/10.3389/fnhum.2016.00039

21. Okamoto $\mathrm{IH}$. Influência da escolaridade na avaliação das praxias numa população idosa normal [mestrado\}. Universidade Federal de São Paulo; 1997.

22. Reis A, Petersson KM, Castro-Caldas A, Ingvar M. Formal schooling influences two- but not three-dimensional naming skills. Brain Cogn. 2001;47(3):397-411. https://doi.org/10.1006/brcg.2001.1316

23. Arévalo A, Perani D, Cappa SF, Butler A, Bates E, Dronkers N. Action and object processing in aphasia: from nouns and verbs to the effect of manipulability. Brain Lang. 2007;100(1):79-94. https://doi.org/10.1016/j.bandl.2006.06.012

24. Buxbaum LJ, Kyle K, Grossman M, Coslett HB. Left inferior parietal representations for skilled hand-object interactions: evidence from stroke and corticobasal degeneration. Cortex. 2007;43(3):411-23. https://doi.org/10.1016/S0010-9452(08)70466-0

25. Frey SH. What puts the how in where? Tool use and the divided visual streams hypothesis. Cortex. 2007;43(3):368-75. https://doi.org/10.1016/S0010-9452(08)70462-3

26. Ardila A, Rosselli M, Rosas P. Neuropsychological assessment in illiterates: visuospatial and memory abilities. Brain Cogn. 1989;11(2):147-66. https://doi.org/10.1016/0278-2626(89)90015-8

27. Hermsdörfer J, Terlinden G, Mühlau M, Goldenberg G, Wohlschläger AM. Neural representations of pantomimed and actual tool use: evidence from an event-related fMRI study. Neuroimage. 2007;36 2:T109-18. https://doi.org/10.1016/j.neuroimage.2007.03.037

28. Duffy RJ, Duffy JR. An investigation of body part as object (BPO) responses in normal and brain-damaged adults. Brain Cogn. 1989;10(2):220-36. https://doi.org/10.1016/0278-2626(89)90054-7

29. Ochipa C, Rothi LJ, Heilman KM. Ideational apraxia: a deficit in tool selection and use. Ann Neurol. 1989;25(2):190-3. https://doi.org/10.1002/ana.410250214

30. Wang L, Goodglass H. Pantomime, praxis, and aphasia. Brain Lang. 1992;42(4):402-18. https://doi.org/10.1016/0093-934X(92)90076-Q 